\title{
ЦИФРОВИЗАЦИЯ: РОЛЬ И ЗНАЧЕНИЕ ДЛЯ НАСЕЛЕНИЯ РЕГИОНОВ И ПЕРВЫЕ ПРОБЛЕМЫ ВНЕДРЕНИЯ В МУНИЦИПАЛЬНОМ УПРАВЛЕНИИ
}

\section{DIGITALIZATION: THE ROLE AND SIGNIFICANCE FOR THE POPULATION OF REGIONS AND THE FIRST PROBLEMS OF IMPLEMENTATION IN MUNICIPAL MANAGEMENT}

\section{E. Polyanskaya E. Sharko}

Summary. In this article, the authors discuss issues related to the formation and development of digitalization of state municipal bodies in the subjects of the Federation. The role and importance of popularization of public services for the population through information and communication technologies is proved. The authors performed a retrospective analysis of the dynamics of development and use of municipal information portals in order to obtain services or request open official information. The level of satisfaction with municipal services received in this way in various regions of the country is also given. The result of the study is an assessment of digital inequality in Russia and shows that at the moment the digitalization gap is regionally insignificant.

Keywords: digitalization, ICT, municipal authorities, public services, population, users, active citizen, interaction of authorities and the population.

\section{«山} ифровизацию» стоит рассматривать как инструмент, а не как самоцель. При системном государственном подходе «цифровые» технологии будут значительно стимулировать развитие открытого информационного общества как одного из существенных факторов развития демократии в России, повышение производительности, экономического роста, создание рабочих мест, а также повышение качества жизни граждан Российской Федерации.

«Цифровизация» России нуждается в новых формах солидарности, партнерства и сотрудничества. На основании проанализированных документов по созданию «цифровых» пространств в Европе и мире ниже сформулированы основные принципы цифровизации, которые должны, прежде всего, воплощаться на государственном уровне в виде диджитализации всех форм государственного и муниципального управления.
Полянская Елена Евгеньевна

К.э.н., дочент, с.н.С., Московский государственный университет имени М. В. Ломоносова

el.polyanskaya@mail.ru

Шарко Елена Романовна

К.э.н., Московский государственный университет имени М.В. Ломоносова ersharko@yandex.ru

Аннотация. В данной статье авторы раскрывают вопросы, связанные с формированием и развитием цифровизации государственных муниципальных органов в субъектах федерации. Доказана роль и значение в популяризации государственных услуг для населения посредством информационно-коммуникационных технологий. Авторы выполнили ретроспективный анализ динамики освоения и использования информационных муниципальных порталов с целью получения услуг или запроса открытой официальной информации. Также приводится степень удовлетворенности полученных таким образом муниципальных услуг в различных регионах страны. Результатом исследования служит оценка цифрового неравенства в России и показано, что на сегодняшний момент разрыв цифровизации регионально незначителен.

Ключевые слова: цифровизация, ИКТ, муниципальные органы, государственные услуги, население, пользователи, активный гражданин, взаимодействие органов власти и населения.

Соблюдение этих принципов будет определяющим для создания, реализации и использования преимуществ, которые предоставляют «цифровые технологии». Создание идей, ИТ-продуктов, программного кода, цифровых услуг - это примеры использование интеллекта, создающего продукты с высокой добавленной стоимостью, другими словами, это примеры капитализации знаний, то есть проявление «экономики знаний», а не экономики природных ресурсов.

Ключевой принцип успешной политики в этой сфере - это не регулирование или формальное отношение, а попечительство с целью развить, приумножить и использовать возможности и наработки ИКТ-компаний (локальных и международных) для конкурентоспособности и эффективности всех других компаний, то есть компаний из других секторов экономики. 
Структура рынка ИКТ очень дифференцирована. Это десятки видов деятельности, каждая из которых способна капитализироваться и «жить» отдельно от других (генерация идеи, дизайн, создание продуктов и услуг, тестирование, интеграция, телеком-провайдеры и т. д). Каждый вид деятельности имеет свою специфику, проблемы, рынки. Таким образом, модели для поддержки, развития и стимулирования различны по своей сути. Итак, «цифровизация» России - это вопрос развития внутреннего рынка потребление продукции и услуг сферы ИКТ. Нет рынка - нет «цифровизации», нет «цифровизации» - нет эффективной и конкурентоспособной экономики.

Россия - огромная страна, и говорить о дифференциальном развитии ее всех федеральных округов не приходится - это очевидно, в результате чего возникает, кроме эконмического и социального, еще и цифровое неравенство. Курс на полный переход к цифровым технологиям во всех отраслях экономики может быть осуществлен по двум сценариям.

Базовый сценарий предполагает инерционное продолжение тенденций восприятия инновационной экономики, развития человеческого капитала, цифровизации экономики как неприоритетных, что будет в дальнейшем приводить к трудовой миграции и оттоку «мозгов», неэффективной экономики, низкой конкурентоспособности, а государство, которое если и будет осуществлять стандартные и формальные шаги, то для ощутимого роста их будет недостаточно. Этот сценарий будет иметь лишь незначительное влияние на модернизацию экономики, развитие рынка инноваций, инновационного предпринимательства, и общего состояния «цифровизации» страны.

Форсированный сценарий предусматривает устранение законодательных, институциональных, фискально-налоговых, валютно-денежных барьеров, препятствующих развитию инновационной экономики «цифровизации», принятие мощных мер по стимуляции «цифровизации» секторов экономики и бизнеса, инициация государством масштабных трансформационных инициатив и проектов «цифровизации» В т.ч. на базе современных моделей государственно-частного партнерства.

Главной мотивацией государства пойти по форсированному сценарию развития должна стать способность «цифровых» технологий влиять на производительность и эффективность экономики и бизнеса. Отрасли, что их используют, растут в 2-4 раза быстрее, чем в среднем по отраслям. Сферы жизнедеятельности (образование, медицина, транспорт и т.д.), которые модернизируются благодаря «цифровым» технологиям, становятся намно- го эффективнее и создают новую ценность и качество, которые очень часто приводят к полной трансформации старой системы [13].

Многое уже сделано: сегодня во многих регионах есть федеральные порталы и сайты, которые позволяют получать государственные услуги высокого качества, общедоступную официальную информацию и даже посредством обратной связи влиять на развитие и совершенствование этих электронных систем. Хорошо организованное взаимодействие органов муниципальной и региональной власти с населением является важнейшим фактором привлечения граждан к решению вопросов местного значения, их активного участия в решении проблем на местах, учету мнений жителей, их инициатив и предложений. Такое взаимодействие необходимо обеим сторонам, так как позволяет органам местного самоуправления строить свою работу исходя из реальных проблем, которые волнуют население, выявлять и ранжировать приоритеты решения стоящих задач и проблем развития территории в целом, расширять объем и качество оказываемых услуг в соответствии с потребностями граждан и др. Население при таком взаимодействии получает информацию о деятельности местных органов и имеющихся проблемах, о планах властей, о предоставляемых услугах и пр. Кроме того, граждане получают возможность находиться в режиме диалога с властью и доносить до нее свои проблемы, участвовать в решении задач территории совместно с органами власти.

Взаимодействие власти и граждан осуществляется путем открытого обсуждения важных и актуальных проблем, информирования граждан о принятых решениях, участия граждан в выработке решений, проведения экспертной оценки принимаемых решений, анализ и совместное обсуждение последствий принимаемых решений, выявление отношения граждан к принятым решениям, публикации отчетов органов власти о работе и реализованных планах и др.

Сотрудничество органов власти и населения реализуется через прямые и обратные коммуникационные связи. Целевые установки, задачи и информирование граждан составляют содержание прямых связей, а оформленная реакция населения на разрабатываемую и проводимую политику, действия или бездействие властей поступает через обратные связи.

При непосредственном взаимодействии власти и населения происходит реальная оценка власти гражданами. Впечатление, которое остается у граждан от общения со служащим о знании им тех или иных вопросов, его личностных качествах, готовности оказать содействие и помощь в решении вопроса и др., что в совокупно- 
сти свидетельствует об уровне компетенции работника и в конечном итоге, влияет на формирование положительного (или отрицательного) образа власти и повышает уровень доверия к ней.

Взаимодействие граждан с органами власти невозможно без доверия к органам управления и их должностным лицам. Доверие к власти во многом определяется открытостью ее при осуществлении ее деятельности и решении вопросов, затрагивающих интересы граждан. Между тем, открытость органов власти и региональной, и местной присутствует в их деятельности далеко не всегда. В частности, решение многих вопросов в регионах и в муниципальных образованиях связано с привлечением финансовых ресурсов, в частности, бюджетных средств, которых, как правило «на все» не хватает. Однако, население не всегда доверяет этому, так как не имеет доступа к соответствующей информации. Возникают конфликты, для устранения которых необходимо проводить открытую политику, постоянно взаимодействовать с населением, расширять, используя современные ИКТ, возможности для получения достоверной информации гражданами.

Однако в настоящее время еще не все регионы построили действенную и эффективную систему открытости. Научно-исследовательский финансовый институт (НИФИ) ${ }^{1}$ на протяжении ряда лет проводит оценку уровня открытости бюджетных данных субъектов РФ

Результаты оценки уровня открытости бюджетных данных субъектов Российской Федерации по разделу Первоначально утвержденный бюджет за 2019 год [6] показали, что наибольшее число баллов набрали 37 регионов (из 85), которые вошли:

- в группу А: очень высокий уровень открытости бюджетных данных группу. Из них максимальный балл получили 12 регионов - Белгородская область, Вологодская область, Мурманская область, Республика Адыгея (Адыгея), Республика Крым, Астраханская область, Ростовская область, Республика Башкортостан, Оренбургская область, Саратовская область, Ямало-Ненецкий автономный округ, Республика Алтай;

- в группу В: высокий уровень открытости бюджетных данных вошли 22 региона, из которых наилучшие результаты у Ярославской, Архангельской и Псковской областей;

- в группу С: средний уровень открытости бюджетных данных 23 субъекта РФ. Наилучшие результаты здесь у Новгородской области и Приморского

НИФИ - Федеральное государственное бюджетное учреждение «Научно-исследовательский финансовый институт» Министерства финансов Российской Федерации края. Обе столицы заняли места во второй половине списка из 85 регионов: Санкт-Петербург на 55 месте, Москва - на 71;

- В группа D: низкий уровень открытости представлена четырьмя регионами: Пермский край, Кировская область, Республика Тыва, Томская область;

- в группу Е: очень низкий уровень открытости бюджетных данных вошла одна - Орловская область.

Для повышения уровня открытости бюджета в регионах разрабатываются Бюджеты для граждан, которые содержат информацию о проекте бюджета (утвержденном бюджете), внесении изменений, годовом отчете об исполнении бюджета и др., отражающую основные положения в форме, понятной и доступность для большой части населения. Бюджеты для граждан повышают доверие населения к власти и способствуют усилению взаимодействия власти и граждан при решении социально-экономических проблем развития территорий. Однако, разработка таких бюджетов, доведение их до населения и обеспечение обратной связи с гражданами в ходе обсуждений требует, учитывая большие объемы информации, использования соответствующих современных цифровых технологий.

Как показывает практика, в настоящее время механизмы взаимодействия власти и граждан до конца не отрегулированы. Нередки случаи, когда у граждан и их объединений при взаимодействии с местными органами возникает достаточно много проблем.

В ряде случаев непонимание, разногласия и даже конфликты между гражданами и работниками органов власти происходят из-за отсутствия у последних не только необходимых профессиональных знаний, но и навыков работы с населением, включающих умение устанавливать контакт с населением, объяснять свои решения, слышать запросы различных социальных групп, учитывать их мнения и предложения. Нередко работники местных органов управления не расположены к взаимодействию с гражданами, так как считают, что инициативы не всегда целесообразны, а граждане, в большинстве своем, не готово к их реализации и активному участию в решении местных проблем, что рассмотрение предложений граждан и учет их интересов не повышает эффективности работы, а попросту, отвлекает от решения действительно важных проблем.

Однако, нельзя не отметить, что в последнее годы и региональные власти, и органы местного самоуправления постепенно меняют свое отношение к участию граждан в самоуправлении, к взаимодействию с ними. При этом во многих случаях именно органы власти, об- 
ладая необходимыми полномочиями и определенными ресурсами для решения социально-экономических проблем территории, становятся центром взаимодействия местного сообщества. Во многом это объясняется имеющимися примерами положительных результатов, достигаемыми в ходе такого взаимодействия.

Определенные проблемы при взаимодействии граждан с органами власти связаны с разнородностью состава жителей, с различиями в их социальном и материальном положении, с разными запросами и возможностями. Это, в свою очередь, приводит к тому, что разные группы населения по-разному оценивают ту или иную проблему, важность и очередность ее решения, возможность своего участия и др.

Также следует отметить, что разные группы населения не только неодинаково относятся к предполагаемым или проводимым изменениям, но и по-разному проявляют себя при обсуждении вопросов, касающихся нововведений. Практика показывает, что большую активность демонстрируют противники предлагаемых изменений, организуя инициативные группы, устраивая обсуждения, проводя коллективные действия и акции. В то же время сторонники изменений выражают свою позицию слабо и весьма пассивно, вследствие чего она часто не получает четкого выражения и остается незамеченной властями. В результате этого «главными» переговорщиками, взаимодействующими с органами власти со стороны населения, становятся именно противники нововведений.

Власти должны быть заинтересованы в увеличении числа граждан, а также различных групп населения, участвующих в обсуждении предполагаемых к осуществлению проектов, в организации, по существу, общественной экспертизы этих проектов, что, в конечном итоге, позволит достичь наибольшей эффективности при их реализации. Это возможно лишь при обеспечении соответствующей обратной связи власти с населением, которая позволит в полной мере задействовать весь потенциал заинтересованных сторон и отдельных граждан и групп населения.

Именно проблема обратной связи при организации взаимодействия органов власти и граждан выходит в последнее время на одно из первых мест. Федеральным законом [11] определен целый ряд механизмов, обеспечивающих обратную связь, таких как публичные слушания, местные референдумы, опросы и др., используя которые органы власти могут получить от граждан информацию, необходимую в дальнейшей работе о наличии и необходимости решения тех или иных проблем, об оценке работы органов власти и пр., а также задействовать, на основе полученной информации, инициативы граждан.
Говоря о взаимодействии органов власти и населения, мы имеем в виду, как правило, информационное взаимодействие. Это связано, в первую очередь с тем, что в современном обществе информация является важнейшим ресурсом, а развитые информационно-коммуникационные технологии - одним из инструментов повышения эффективности государственного и муниципального управления. Поэтому так важно решение вопросов, связанных с организацией информационно-коммуникационных связей между властью и обществом.

Одним из направлений, обеспечивающим качественно новый уровень организации такого взаимодействия является широкое использование современных информационно-коммуникационных технологий. Внедрение ИКТ в институты власти - одна из главных тенденций современного развития.

Продвижение ИКТ в регионах и муниципальных образованиях требует, в свою очередь, формирования соответствующей инфраструктуры, которая позволит использовать новые возможности цифровых технологий органами власти и населением. Создание информационной инфраструктуры и развитие современных информационно-коммуникационные технологий общества предоставляет принципиально новые возможности для совершенствования системы взаимодействия органов власти и населения.

Внедрение и распространение цифровых технологий расширяет и предоставляет новые возможности и преимущества, как для населения, так и для органов управления.

Для граждан это:

- снижение в большинстве случаев необходимость в непосредственных контактах с чиновниками при решении тех или иных проблем;

- повышения качества и доступности предоставляемых услуг населению;

- сокращение времени получения государственных и муниципальных услуг;

- доступ к получению актуальной информации по широкому кругу вопросов, затрагивающих интересы граждан;

- возможность участия в широком обсуждении различных законопроектов, других правовых актов при их подготовке и выработке решений;

- участие в процессах управления, в доведении до властей общественного мнения;

- получение достоверной и качественной информации о деятельности органов управления;

- повышение уровня прозрачности власти и др.

Для органов власти это: 
- расширение доступа к различной информации, получаемой как от различных властных структур, организаций, так и от граждан;

- возможность быстро доносить необходимую информацию до населения;

- организация обратной связи с гражданами и различными организациями;

- быстрота обработки, систематизации и анализа больших объемов информации;

- устранение необходимости осуществлять управляющее воздействие по длинным цепочкам, состоящим из чиновников;

- уменьшение, как числа самих чиновников, так и расходов на их содержание;

- снижение зависимость служащих от вышестоящих должностных лиц;

- сведение к минимуму возможности для злоупотреблений со стороны должностных лиц, которые могут возникать при личных контактах с гражданами, пои решении тех или иных проблем;

- повышение качества и доступности предоставляемых услуг населению и организациям, повышения результативности, качества и прозрачности работы государственного аппарата;

- снижение уровня коррупции;

- повышение доверия к власти со стороны населения и др.

В настоящее время во многих субъектах РФ региональными и местными органами власти проводится определенная работа по организации такой «обратной связи», по вовлечению граждан в процессы местного самоуправления: реализуются проекты поддержки местных инициатив, выдвигаемых гражданами, «народный бюджет», когда жители участвуют в выборе конкретных направлений использования денежных средств и др. Ведется и по внедрению в эти процессы новых цифровых технологий, по использованию ИКТ при организации взаимодействия органов власти с населением. Одновременно реализуются масштабные программы и проекты по созданию государственных информационных систем, обеспечивающих автоматизацию процедур сбора, обработки и хранения сведений, необходимых для выполнения органами государственной власти основных функций.

Субъекты РФ разработали концепции информатизации регионов. В органах региональной власти субъектов России созданы специальные подразделения (Департаменты), занимающиеся вопросами информационных технологий и цифрового развития, отделы информационных систем и электронного правительства, действуют порталы государственных услуг, информационные системы государственных и муниципальных платежей и др. В регионах разрабатываются соответствующие нормативные акты по внедрению информационно-коммуникационных технологий, как на уровне субъектов РФ, так и на муниципальном уровне.

Работа эта проводится на основе принятых в последние годы в стране документов, таких как: Государственная программа «Информационное общество (2011-2020 годы)» [7], «Цифровая экономика Российской Федерации» [4], Стратегии развития информационного общества в Российской Федерации Концепции региональной информатизации [5] и Доктрина информационной безопасности РФ [8]; прияты ФЗ «Об информации, информационных технологиях и о защите информации» [9] и «Об обеспечении доступа к информации о деятельности государственных органов и органов местного самоуправления» [10] и др.

На уровне муниципальных образований, работа по внедрению ИКТ, направлена в первую очередь, на создание систем информационного обслуживания при оказании услуг населению. Об этом свидетельствует и отчетность муниципальных органов перед региональными по внедрению и развитию ИКТ, где используются такие показатели, как общее количество заявлений на получение муниципальных услуг с ЕПГУ (Единого портала государственных услуг), количество заявлений с ЕПГУ по услуге «Запись на прием к врачу», количество заявлений с ЕПГУ по услуге «Электронный дневник», количество заявлений с ЕПГУ по услуге «Запись актов гражданского состояния», количество заявлений с ЕПГУ по услугам в сфере строительства, доля заявлений поданных через мобильное приложение Госуслуги, количество граждан (старше 14 лет), прошедших процедуру подтверждения личности, количество межведомственных запросов, доля документов, отправленных в электронной форме от общего числа исходящих документов и др.

Говоря об использовании цифровых технологий при взаимодействии органов власти и населения, нельзя не сказать об опыте города Москвы по эффективной и успешной организации обратной связи и такого взаимодействия, связанном с реализацией московского проекта «Активный гражданин». Данный проект был разработан в 2014 году по инициативе Правительства Москвы. Цель проекта - выявления мнений и оценок граждан по различным вопросам, требующим решения путем проведения открытых голосований, опросов, референдумов. По количеству активных пользователей и объему вопросов, выносимых на обсуждение, проект является уникальным в мире и отмечен несколькими престижными наградами, в том числе Smart Cities Awards-2015.

Каждую неделю по поручению мэра, департаментов, префектур и управ районов жителям предлагают- 
Таблица 1. Взаимодействие населения с органами государственной власти и органами местного самоуправления для получения услуг

\begin{tabular}{|c|c|c|c|c|c|c|c|c|}
\hline $\begin{array}{l}\text { Взаимодействовали (\% от общей } \\
\text { численности населения) }\end{array}$ & 2015 & 2016 & 2017 & 2018 & $2019 *$ & $\begin{array}{l}\text { Темп роста } \\
17 / 15\end{array}$ & $\begin{array}{l}\text { Темп } \\
\text { роста } \\
19 / 18\end{array}$ & $\begin{array}{l}\text { Темп роста } \\
19 / 15\end{array}$ \\
\hline Всего & 46,4 & 56,1 & 65,7 & 67,2 & 76,8 & $142 \%$ & $114 \%$ & $166 \%$ \\
\hline $\begin{array}{l}\text { через Интернет с использованием } \\
\text { официальных сайтов и порталов } \\
\text { государственных и муниципальных } \\
\text { услуг) }\end{array}$ & 18,3 & 26,8 & 32,1 & 45,1 & 57,05 & $175 \%$ & $126 \%$ & $312 \%$ \\
\hline $\begin{array}{l}\text { В многофункциональных центрах } \\
\text { государственных и муниципальных } \\
\text { услуг (МФЦ) }\end{array}$ & 7,1 & 10,8 & 13,7 & 15,3 & 16,2 & $193 \%$ & $106 \%$ & $228 \%$ \\
\hline путем личного посещения & 21,1 & 22,5 & 24 & 16 & 18 & $114 \%$ & $113 \%$ & $85 \%$ \\
\hline Не взаимодействовали & 53,5 & 39,9 & 30,2 & 23,6 & 8,75 & $56 \%$ & $37 \%$ & $16 \%$ \\
\hline
\end{tabular}

*- прогнозное значение

Источник: составлено авторами на основе [10]

Таблица 2. Доля населения, взаимодействующего с органами государственной власти и местного самоуправления для получения услуг (\% от общей численности населения)

\begin{tabular}{|c|c|c|c|c|c|c|c|c|}
\hline \multirow{3}{*}{ Субъект } & \multicolumn{8}{|c|}{ Доля взаимодействующих граждан } \\
\hline & \multicolumn{2}{|c|}{ Bcero } & \multicolumn{2}{|c|}{ Лично } & \multicolumn{2}{|c|}{ Через Интернет } & \multicolumn{2}{|c|}{ Через МФЦ } \\
\hline & 2016 & 2017 & 2016 & 2017 & 2016 & 2017 & 2016 & 2017 \\
\hline Российская Федерация & 56,1 & 65,7 & 22,5 & 24,0 & 28,8 & 42,3 & 11,8 & 18,9 \\
\hline \multicolumn{9}{|l|}{ Федеральные округа: } \\
\hline Центральный & 55,0 & 69,7 & 18,3 & 22,0 & 31,0 & 49,7 & 12,6 & 22,2 \\
\hline Северо-Западный & 42,5 & 57,0 & 18,9 & 21,2 & 18,6 & 32,0 & 7,4 & 17,4 \\
\hline Южный & 65,6 & 68,1 & 23,8 & 20,7 & 23,8 & 43,8 & 24,5 & 29,1 \\
\hline Северо-Кавказский & 49,0 & 54,9 & 15,5 & 15,7 & 22,3 & 29,1 & 15,7 & 21,5 \\
\hline Приволжский & 64,5 & 69,9 & 27,9 & 25,9 & 35,7 & 47,0 & 8,0 & 14,4 \\
\hline Уральский & 71,0 & 77,2 & 32,7 & 35,7 & 37.7 & 45,5 & 14,3 & 20,3 \\
\hline Сибирский & 45,7 & 59,0 & 23,5 & 27,5 & 18,6 & 35,2 & 6,4 & 11,3 \\
\hline Дальневосточный & 42,4 & 48,3 & 16,2 & 21,3 & 20,3 & 27,3 & 8,9 & 12,3 \\
\hline
\end{tabular}

Источник: составлено авторами на основе [10]

ся на обсуждение важные для города вопросы. Проект имеет официальный сайт «Активный гражданин».

Граждане, участвующие в опросах и голосованиях могут следить за ходом голосований и контролировать итоговые показатели, проверять правильность фиксации и учета, отданного ими голоса, отслеживать в онлайн режиме общую картину и динамику результатов, что позволяет им убедиться в открытости и достоверности всего голосования [2].
Принять участие в голосовании могут все, кто проживает в Москве, вне зависимости от наличия прописки. За участие в голосовании начисляются баллы. Набравшим 1000 баллов пользователям присваивается статус «Активный гражданин» и возможность обменивать баллы на городские услуги, такие, например, как парковочные часы, посещение театров и музеев и др.

Следует отметить, что итоги опросов напрямую влияют на дальнейшие решения властей и их действия. 
Таблица 3. Цели использования Интернета при взаимодействии граждан с органами власти для получения государственных и муниципальных услуг (\% от общей численности населения)

\begin{tabular}{|l|l|l|l|l|l|}
\hline Государственные услуги и запросы & $\mathbf{2 0 1 5}$ & $\mathbf{2 0 1 6}$ & $\mathbf{2 0 1 7}$ & $\mathbf{2 0 1 8}$ & $\mathbf{2 0 1 9 *}$ \\
\hline $\begin{array}{l}\text { Получение информации через официальные сайты } \\
\text { и порталы государственных и муниципальныхуслуг }\end{array}$ & 65,8 & 66,8 & 69,3 & 72,4 & $\mathbf{7 4 , 2}$ \\
\hline Запись на прием к должностным лицам через сеть Интернет & 44,7 & 50,6 & 57,5 & 59,2 & $\mathbf{6 5 , 6}$ \\
\hline Платежи (пошлины, налоги, штрафы) & 30 & 35,9 & 40,2 & 42,8 & 47,9 \\
\hline Скачивание типовых форм для заполнения & 26,6 & 27 & 30,8 & 34,5 & 36,6 \\
\hline $\begin{array}{l}\text { Отправление документов в государственные } \\
\text { и муниципальные органы и организации в электронном виде }\end{array}$ & 26,5 & 24,2 & 28,6 & 32,1 \\
\hline $\begin{array}{l}\text { Получение на портале государственных и муниципальных } \\
\text { услуг результатов предоставления услуг в электронном виде, } \\
\text { Включая получение в личный кабинет }\end{array}$ & 16,2 & 19,3 & 21,4 & 25,7 \\
\hline $\begin{array}{l}\text { Получение уведомлений с порталов услуг на электронную } \\
\text { почту и в SМS-сообщении }\end{array}$ & 10,1 & 15 & 17,3 & 28,3 \\
\hline
\end{tabular}

* - прогнозное значение

Источник: составлено авторами на основе [10]

Таблица 4. Оценка населением качества государственных и муниципальных услуг, получаемых через Интернет

\begin{tabular}{|c|c|c|c|c|c|c|}
\hline \multirow{3}{*}{ Субъект } & \multicolumn{6}{|c|}{$\begin{array}{l}\text { удовлетворенность качеством услуг (\% от общей численности населения, } \\
\text { получающего услуги через Интернет) }\end{array}$} \\
\hline & \multicolumn{2}{|c|}{ полностью } & \multicolumn{2}{|c|}{ частично } & \multicolumn{2}{|c|}{ Не удовлетворены } \\
\hline & 2016 & 2017 & 2016 & 2017 & 2016 & 2017 \\
\hline Российская Федерация & 66,1 & 70.5 & 32,4 & 28,4 & 1,4 & 1,1 \\
\hline \multicolumn{7}{|l|}{ Федеральные округа: } \\
\hline Центральный & 68,0 & 71,1 & 30,7 & 27,3 & 1,3 & 1,6 \\
\hline Северо-Западный & 67,6 & 64,3 & 31,4 & 34,7 & 1,0 & 1,0 \\
\hline Южный & 60,9 & 73,9 & 37,2 & 25,3 & 1,8 & 0,8 \\
\hline Северо-Кавказский & 60,1 & 64,7 & 36,0 & 34,2 & 3,9 & 1,1 \\
\hline Приволжский & 68,1 & 72,5 & 30,9 & 26,9 & 1,1 & 0,7 \\
\hline Уральский & 65,2 & 66,8 & 33,9 & 32,4 & 0,9 & 0,9 \\
\hline Сибирский & 69,6 & 72,7 & 28,9 & 26,2 & 1,5 & 1,1 \\
\hline Дальневосточный & 54,2 & 63,6 & 43,3 & 34,9 & 2,5 & 1,4 \\
\hline
\end{tabular}

Источник: составлено авторами на основе [10]

Результаты передаются в профильные ведомства для принятия соответствующих приказов и постановлений. Сформировалось несколько групп тем, среди которых «законопроекты по различным проблемам», «благоустройство», «социальная защита», «образование» и др.

Непосредственное реагирование власти на мнение граждан является одной из главных причин того, что данный проект пользуется популярностью и доверием у жителей города. Каждую неделю к порталу присоединяется несколько тысяч пользователей. К настоящему времени в проекте участвуют уже почти два миллиона жителей, проведено более 2600 голосований и принято почти 80 миллионов мнений граждан, по результатам опросов и голосований выполнено более 1600 решений по различным вопросам [9].

Реализация данного проекта была бы невозможна без использования новых современных цифровых информационно-коммуникационных технологий, позволяющих обрабатывать большие объемы информации и использовать данные результатов анализа с существенно большей эффективностью по сравнению с тра- 
диционными формами хозяйствования. Однако, здесь нельзя не сказать о том, что Москва обладает существенными преимуществами как в плане обеспечения необходимой техникой, программным обеспечением, так и квалифицированными кадрами, которые могут работать в новых условиях внедрения цифровой экономики.

Далее мы рассмотрим использование информационно-коммуникационных технологий при взаимодействии населения с органами власти. Как показывает практика, доля населения, взаимодействующего с органами власти, для получения услуг, в последние 5 лет растет. Так, в целом с 2015 г. по 2019 г. она выросла более, чем на $66 \%$ (см. таблицу 1). Взаимодействие осуществляется как посредством личных встреч, личного общения, так и с использованием современных информационно-коммуникационных технологий.

В наибольшей степени растет число граждан, взаимодействующих через Интернет, то есть самостоятельно и через многофункциональные центры (МФЦ), которые созданы органами власти для предоставления гражданам государственных и муниципальных услуг с использованием (ИКТ).

В таблице 2 представлены данные по взаимодействию граждан с органами власти в Федеральных окру$\operatorname{rax}(Ф О)$ РФ.

Из таблицы видно, что доля взаимодействующих с органами власти граждан растет во всех ФО.

Больше всего для получения государственных и муниципальных услуг граждане используют сеть Интернет. Число лиц пользующихся Интернетом для получения услуг растет, как в целом, так и в городской местности и в сельской местности. Однако, в городах таких пользователей больше, чем на селе.

Граждане при взаимодействии с государственными и муниципальными органами власти используют Интернет для получения информации, для записи на прием к должностным лицам, получение услуг и для других целей (см. таблицу 3).

Мы видим, что по всем направлениям отмечается рост, что свидетельствует, с одной стороны о потребности во взаимодействии, а, с другой — о новых возможностях для граждан, предоставляемых новыми ИКТ.

Следует отметить, что подавляющее большинство граждан полностью или частично удовлетворены качеством услуг, которые они имеют возможность получить через сеть Интернет (см. таблицу 4).
Данные таблицы, свидетельствующие о степени удовлетворенности граждан качеством получаемых услуг, подтверждают, что использование современных технологий дает позитивный результат для граждан и способствует более активному вовлечению граждан в процессы взаимодействия через получение таких услуг и, в то же время, существенно облегчает деятельность органов власти, которые при предоставлении услуг также пользуются ИКТ и за счет чего могут в быстром режиме оказывать услуги.

Кроме того, мы видим, что разброс данных, как в целом по РФ, так и по отдельным Федеральным округам весьма невелик. «Цифровой разрыв» наряду с материальным измерением имеет также интеллектуальное и социальное измерения, что означает недостаточное применение фундаментальных компетенций и знаний для пользования новейшими информационными технологиями и эксплуатации их содержимого, а также недостаточные социальные ресурсы для получения достойной позиции в «цифровом мире». Доступ к культуре, туризму, охрану здоровья, трудоустройству происходит все больше и больше с использованием сетевых услуг. Быть лишенным компьютера или доступа к сети Интернет - это потерять не только время, но и деньги. Социальные ресурсы позволяют конструировать автономное применение новейших информационных технологий, как в частном, так и в социальной и профессиональной жизни. Важным является подход, который рассматривает динамический характер этого феномена и характеризует «цифровое неравенство» скорее как социальный процесс, чем как стационарное состояние общества [12]. Динамичный характер этого явления является важным, поскольку он позволяет тщательно исследовать распространенную идею, согласно которой существует четкое и стабильное разграничение между теми, кто имеет материальный и интеллектуальный доступ к «цифровому миру» через новейшие информационные технологии, и теми, кто его не имеет. Разделяют «цифровой разрыв», обусловленный, с одной стороны, неравными возможностями доступа к сети Интернет и новейших информационных технологий - «цифровой разрыв первого уровня», а с другой - неровностями, которые развиваются у пользователей сети Интернет, которые уже имеют доступ к сети Интернет - «цифровой разрыв второго уровня». В России исследования показали, что работа по внедрению ИКТ идет достаточно равномерно на различных территориях страны и граждане получают услуги примерно одного качества.

Говоря об использовании цифровых технологий, в частности, сети Интернет и населением и органами власти, необходимо отметить, что в последние годы в стране наблюдается рост числа персональных компьютеров (ПК), подключений к Интернету, как в домашних хозяйствах, так и в организациях. 


\section{ЛИТЕРАТУРА}

1. Информационное общество в Российской Федерации. 2018: статистический сборник / М. А. Сабельникова, Г. И. Абдрахманова, Л. М. Гохберг, 0. Ю. Дудорова и др.; Росстат; Нац. исслед. ун-т «Высшая школа экономики». Электрон. текст дан. (9 Мб). М.: НИУ ВШЭ, 2018.

2. Полянская Е. Е. Использования цифровых технологий в организации взаимодействия органов власти и населения // Проблемы и перспективы использования цифровых технологий в региональном и муниципальном управлении: коллективная монография / Под ред. В. К. Ковальчука, А.П. Сысоева, А. И. Усова, М. С. Халикова. 270 с. С. $116-138$.

3. Портал «Активный гражданин. URL: https://ag.mos.ru/home (дата обращения 15.04.2020).

4. Постановление Правительства РФ «0бутверждении государственной программы Российской Федерации «Информационное 0бщество» от 15.04 .2014 N313 (ред. от 31.03.2020) // Нормативно-правовая справочная система «Консультант Плюс».URL: http://www.consultant.ru/document/cons_doc_LAW_162184 (дата обращения 02.04.2020).

5. Распоряжение Правительства РФ «0б утверждении Концепции региональной информатизации» от 29.12.2014 N2769-р (ред. от 18.10.2018) // Нормативно-правовая справочная система «Консультант Плюс». URL: http://www.consultant.ru/document/cons_doc_LAW_173678 (дата 0бращения 02.04.2020).

6. Рейтинг субъектов Российской Федерации по уровню открытости бюджетных данных за 2019 год // HИФИ. URL: https://nifi.ru/ru/rating (дата обращения 12.04.2020).

7. Указ Президента РФ «0 Стратегии развития информационного общества в Российской Федерации на 2017-2030 годы» от 09.05.2017 N203 // Нормативно-правовая справочная система «Консультант Плюс». URL: http://www.consultant.ru/document/cons_doc_LAW_216363 (дата 06ращения 02.04.2020).

8. Указ Президента РФ «0б утверждении Доктрины информационной безопасности Российской Федерации» 0т 05.12.2016 N646 // Нормативно-правовая справочная система «Консультант Плюс». URL: http://www.consultant.ru/document/cons_doc_LAW_208191 (дата обращения 02.04.2020).

9. Федеральный закон «0б информации, информационных технологиях и о защите информации» от 27.07.2006 N149-Ф3 (последняя редакция) // Нормативно-правовая справочная система «Консультант Плюс». URL: http://www.consultant.ru/document/ cons_doc_LAW_61798 (дата 0бращения 02.04.2020).

10. Федеральный закон «0б обеспечении доступа к информации о деятельности государственных органов и органов местного самоуправления» 0т 09.02.2009 N8-Ф3 (последняя редакция) // Нормативно-правовая справочная система «Консультант Плюс». URL: http://www.consultant.ru/document/cons_doc_ LAW_84602 (дата обращения 02.04.2020).

11. Федеральный закон «06 общих принципах организации местного самоуправления в Российской Федерации» 0т 06.10.2003 N131-Ф3 (ред. от 27.12.2019) // Нормативно-правовая справочная система «Консультант Плюс». URL: http://www.consultant.ru/document/ cons_doc_LAW_44571 (дата 06ращения 02.04.2020).

12. Шарко Е.Р., Савельев И. И. Применение цифровых технологий при формировании стратегии отечественных компаний // Научные исследования экономического факультета. Электронный журнал. 2019. Т. 11. № 2 (32). С. 107-121.

13. Шерешева М.Ю., Савельев И. И., Шарко Е. Р. Роль цифровых технологий в эффективном формировании взаимоотношений муниципальной власти с местными сообществами // Проблемы и перспективы использования цифровых технологий в региональном и муниципальном управлении: коллективная монография / Под ред. В. К. Ковальчука, А. П. Сысоева, А. И. Усова, М. С. Халикова. 270 с., С. 65-72.

( Полянская Елена Евгеньевна ( el.polyanskaya@mail.ru ), Шарко Елена Романовна ( ersharko@yandex.ru ).

Журнал «Современная наука: актуальные проблемы теории и практики» 